\title{
We Have Passed This Way Before: A Response to "Dollar Dilemmas During the Downturn-A Financial Crossroads for College Sports"
}

\author{
Mary Jo Kane \\ University of Minnesota
}

\section{Introduction}

In his timely and provocative essay- "Dollar Dilemmas During the Downturn: A Financial Crossroads for College Sports"-Andrew Zimbalist examines in great detail the numerous and seemingly intractable financial challenges facing intercollegiate athletics, particularly at the Division I level, during the worst fiscal crisis this country has endured since the Great Depression. As part of his overall analysis, Zimbalist also suggests solutions to the current financial crisis while offering an assessment of "whether or not these reforms are politically practicable" (2010, p. 1). A central premise of Zimbalist's critique is that Football Bowl Subdivision (FBS) budgets-especially when accounting for such expenditures as indirect costs, debt service, and capital costs-incur significant deficits on a recurring basis. He further argues that the gap between expenses and revenues is growing at the vast majority of universities, and that "all but a handful of schools' athletic departments run a deficit when properly accounted" (p. 1). Finally, Zimbalist makes a compelling case that the divide between rich and poor schools continues to widen at an alarming pace.

What I thought was particularly impressive (not to mention helpful) about Professor Zimbalist's paper was the overwhelming amount of empirical data he provides to support his central arguments. Citing 2009 National Collegiate Athletic Association (NCAA) figures, Zimbalist points out that among all 119 FBS Division I schools, only 25 athletic departments generated a net operating surplus (Fulks, 2009). His statistical data are supported by other sources as well. For example, in terms of the gap between rich and poor, the current financial structure in college athletics has created a growing class structure whereby schools in wealthy sports conferences, when compared with struggling ones, generate approximately 14 times as much revenue as do schools from the poorest athletic conferences (Weiner \& Suggs, 2009). What was also useful about Professor Zimbalist's critique was that he took on—and successfully refuted—arguments advanced by supporters of big-time college sports who counter concerns about the state of intercollegiate 
athletics with claims that successful sports programs generate significant donations to a university overall and substantially increase student applications.

Arguing that "business as usual" is unsustainable, Zimbalist addresses today's financial challenges and pitfalls by offering a number of policy reforms to put college athletics on the road to fiscal stability. These reforms range from reducing the number of scholarships in Division I football, to regulating the salaries of "power coaches" in football and men's basketball through an antitrust exemption, to creating a playoff system in FBS football that would end the "highly flawed, unfair and anticompetitive BCS five-game bowl system" (2010, p. 17). To these suggestions I say two things-Hear! Hear! and Good luck! Zimbalist ends his paper by discussing the prospects for implementing real, meaningful structural reform. Though he is clearly not politically naïve to the challenges before us, he argues that what is different in today's climate is the fact that the "financial stakes have multiplied and the bottom line has become acutely more problematic" (p. 21).

Regarding my own assignment-which is to serve as a reactor to this important keynote address-I take up Jay Coakley's invitation to "build on, qualify, and/or offer a constructive critique and to do so in a way that is informative, provocative, and even challenging while not becoming unduly polemical." In the analysis provided below, I will indeed try to offer a constructive critique that is informative and challenging, though it is difficult to ask a faculty member to avoid being polemical, particularly given this forum and this topic. Such a request is perhaps even more difficult than trying to bring about real reform in big-time college athletics.

\section{Déjà Vu All Over Again}

As I was reading through Professor Zimbalist's paper I had one fairly consistent reaction even as I was agreeing with almost everything he had to say. In the words of that preeminent sage from the world of sports, Yogi Berra: "This feels like déjà vu all over again." Don't misunderstand my point. My reaction is by no means a criticism of Zimbalist's analysis. He was simply (and nobly) taking on, in his words, a "sufficiently ambitious chore," meaning to examine various ways college sports can tackle current financial challenges through new policies and constructive change. But as we know all too well, calls for reform have been around since the days of Teddy Roosevelt (NCAA, 2009b). More recent attempts occurred in 1975 when the NCAA convened a "Special Meeting on Economy in Intercollegiate Athletics" to consider ways to implement serious vs. trim-around-the-edges budget cuts to curtail out-of-control spending (Weiner \& Suggs, 2009). History repeated itself in 1990 when, once again, the NCAA convened a "Special Committee on Cost Reduction" that resulted in reducing the number of scholarships in men's sports - the most significant of which was in football-as well as limiting some coaches' salaries (Weiner \& Suggs, 2009). Sound familiar?

Such attempts at reform, as well as a history-repeats-itself narrative, have not been limited to efforts by the NCAA. From its inception, a primary concern of - not to mention numerous reports from-the Knight Commission has been the financial structures, policies, and spending patterns in intercollegiate athletics. In 1991, the Commission issued what many consider to be a groundbreaking model of reform: Keeping Faith with the Student-Athlete called for the development of a "one-plusthree" approach to governing intercollegiate athletics where fiscal soundness was 
given the same weight as academic integrity and a system of accountability to ensure the well-being of student athletes.

Given this historical background, and the sense that we have "passed this way before," I would challenge us to ask, what is fundamentally (if at least not substantially) different from previous efforts at reform, both in terms of this research colloquium overall and Professor Zimbalist's arguments in particular? Why is this moment in time, as Professor Zimbalist suggests, more critical than in previous eras of reform? In sum, why is "business as usual" not sustainable in today's financial climate any more than it was during the early 1990s?

I ask these questions because one area where I think Professor Zimbalist needs to make a stronger case is demonstrating how (and why) 2010 is a landmark moment for enacting reform. To be fair, he does point out that the "2008-09 global financial crisis and economic downturn have only exacerbated the already untenable situation" (2010, p. 10), and further argues that "what is different now is that the financial stakes have multiplied and the bottom line has become acutely more problematic" (p. 21). Zimbalist is not alone in his assessment on this point. In a recent editorial appearing in the Washington Post, William Kirwan and Gerald Turner, cochairs of the Knight Commission, argued that the most critical issue facing college sports today is not reform of the FBS bowl system, but the sustainability of the current business model, which they describe as "on a path toward meltdown" (Kirwan \& Turner, 2009). They too cite the added pressures of the recession and conclude that "college sports face unprecedented economic challenges." Though I do not disagree with their overall analysis, I suggest that Professor Zimbalist (and other advocates of reform) would be on even stronger ground if, for example, they provided comparative data on widespread and growing budget deficits - as well as gaps between rich and poor schools - from other benchmark moments (e.g., the 1975 and 1990 NCAA "calls for action" cited above). Current data would presumably show that we are indeed in a period of financial crisis that is of greater magnitude than ever before and thus there is greater urgency to truly (and perhaps finally) bring about meaningful and long-lasting reforms.

\section{Are Deeper Measures of Reform Possible?}

In this section I examine Professor Zimbalist's specific suggestions for policy reforms that may contribute not only to fiscal sanity but to a more equitable balance in intercollegiate sports. While doing so, I add new — or at least additional—ideas about the financial reforms Professor Zimbalist highlights, extend or push back on his analysis in some areas, and, in a few instances, suggest alternative ways to frame the overall discussion.

\section{Antitrust Exemption to Limit Coaches' Salaries}

One of the most disturbing data points that Professor Zimbalist outlined had to do with the compensation packages given to head coaches in men's basketball and football. With respect to monetary compensation alone, in today's market, a dozen-plus football coaches exceed $\$ 3$ million in salary, while others exceed $\$ 4$ million with no end in sight. What is perhaps even more disturbing are the results which emerged from a 2009 survey of FBS presidents sponsored by the Knight 
Commission. Clearly recognizing the need for structural reforms, the presidents indicated that head coaches' out-of-control and skyrocketing salaries were the "greatest impediment to [financial] sustainability" in college sports (Knight Commission on Intercollegiate Athletics, 2009, p. 10), and that to address sustainability concerns, "wide, sweeping action" across all FBS schools needed to occur. And what did these same presidents intend to do about the current, and troubling, state of affairs? Apparently not much. Even though university presidents have long argued for more authority within the NCAA, the majority of those surveyed felt they had limited power to change the system in any fundamental way, and more than a few indicated they had little (if any) control over big-time college sports (Moltz, 2009). These results prompted Nathan Tublitz, cochair of the Coalition on Intercollegiate Athletics ${ }^{1}$ to remark: "Why don't some presidents just come out and take a stand?" (quoted in Moltz, 2009).

I suggest there are a number of reasonable — not to mention realistic_-explanations for the pervasive pessimism among university presidents and their unwillingness to "take a stand." I once heard a college president, in the wake of yet another scandal in men's sports, say, "I didn't come [to this particular university] to be the President of Athletics." University presidents have to deal with so many issues during their tenure, from faculty, to state legislatures, to governors, to labor unions, that they shy away from taking on what I presume many of them feel is a force more powerful than nature and something that, in an ideal world, their athletic director would be in control of. And on college campuses nationwide, presidents are not alone in their belief that they were hired to focus on issues more directly tied to the university's mission. As a general rule, presidents face little pressure from their faculty to focus their time, efforts, and resources on what many faculty members feel is (or at least should be) a peripheral concern to top levels of the administration (e.g., the football coach's salary). Most faculty members are simply (and rightly) too busy with their own academic careers to pay much attention to their school's sports program, especially when it comes to issues of reform (Lederman, 2009).

I would also suggest that presidents' reluctance to confront meaningful change is exacerbated by the "culture of the academy" in choosing outsiders vs. insiders. All things being equal, there is often a desire to hire a university president from the outside, meaning someone who has their advanced degrees from another institution. This is in sharp contrast to what typically happens with power coaches and ADs where there tends to be a feeling that we should hire "one of our own," a Michigan Man if you will. The difference between these two cultures matters because it is pretty likely that a college president will not have the same degree of loyalty, commitment, and deep roots to "the old U" that, for example, the football coach who played for and graduated from that same "old U" does.

Finally, even if college presidents banded together to try and put a cap on coaches' salaries, results from the recently released Knight Commission survey make it clear it would not be in the form of antitrust regulation. As Professor Zimbalist himself noted, most presidents $(56 \%)$ were wary of changing federal law as a way to control salaries, presumably because they worry that such an approach would create a "slippery slope" leading to too much government interference. In sum, presidents may feel they need to carefully pick and choose their battles and, as the results from the Knight Commission make abundantly clear, this is one battle they feel they cannot win. 


\section{Reducing the Number of Football Scholarships}

Professor Zimbalist's second recommendation for policy reform that could lead to fiscal solvency involves reducing the number of scholarships-which currently stands at 85-dedicated to FBS football teams. I heartily agree with his analysis on this point, and will provide some examples of my own that will expand upon his argument and make what I hope will be an even stronger case. Zimbalist points out that the average size of an FBS team (including walk-ons) is 117 and makes an appropriate comparison with the NFL where the roster size is capped at 53. In my view, his critique would be even more compelling if, in the future, he were to include the following line of reasoning: If the NFL — the gold standard of the industry - only needs 53 players to compete at the highest level, why do college rosters need to be twice that size to produce a quality product? College football coaches' standard reply to that question is to complain that they need a larger team to compensate for (meaning, are able to replace) injured players. But Professor Zimbalist ably counters that argument by once again relying on powerful data-he cites NCAA Injury Surveillance System Summary reports which indicate that based on the average number of injured players per team there is no justification for current roster sizes. I would add an equally powerful argument to counter coaches' claims that they need such large squads. According to NCAA Division I travel policies, the maximum size of a football traveling squad is 60 (NCAA, 2009a). Why would a coach who truly believes he needs a roster of $100+$ players to successfully compete agree to doubly disadvantage himself? What I mean here is that when you are playing an away game you begin with a competitive disadvantage. Why would you choose to compound that disadvantage by coming in with a smaller squad to compete against the home team? I suggest the answer has a lot to do with saving money, as opposed to really believing that a team of 60 players is insufficient against a team of 117 .

Professor Zimbalist points out that "if football scholarships were cut to 60, the average college would save approximately $\$ 750,000$ annually" (2010, p. 16). But there are additional — and equally important—reasons to reduce the number of scholarships set aside for FBS teams and at considerably larger savings. If you reduced the size of the football team by, say, one-third, you could also reduce the enormous infrastructure that keeps the football engine going. For example, athletic departments typically employ hundreds of individuals ranging from academic advisors, to athletic trainers, to sports information directors, to countless administrators, assistant coaches, and other staff. Given the size of today's football teams-as well as the high priority they are given within an athletic department - the bulk of those employees focus their efforts on football. The key point here is that if we "downsized" football by at least a third, the number of individuals needed to support the program could also be reduced proportionately and the annual savings would be significant. I would urge Professor Zimbalist, and other sports economists who do research in this area, to more precisely calculate what those savings would actually be.

There are three additional points that underscore the need to reduce the size of the football team and thus capture significant and recurring savings. First, the "beauty" of downsizing is that expenses would be significantly reduced but revenues would essentially remain stable or even increase. Smaller rosters would not negatively impact conference revenue sharing or television contracts. In addition, it 
is hard to imagine that people would no longer buy sports apparel associated with their college team because they were upset about the smaller squad size. Nor would they stop attending games or, God forbid, cancel season tickets that have been in their family for generations. Second, this is a policy change that could actually be implemented. It would not, for example, require federal legislation. It would be entirely within the purview of the NCAA, the only organization which has the broad-based power and authority to enact this long-overdue reform, one which would lead to profound and lasting change. My third and related point is that the proposed policy change needs to come directly from the NCAA as a nationwide mandate because otherwise schools and athletic conferences may feel they are being asked to unilaterally (and thus unfairly) disarm.

\section{Introduction of a Playoff System in FBS Conferences}

This was one of the strongest parts of Professor Zimbalist's critique. In spite of my many concerns and objections to big-time college football, I am also a bigtime college football fan. I, like millions of Americans, am deeply frustrated with what is clearly a flawed and unfair system with no legitimate rationale. Professor Zimbalist takes us through a logical, step-by-step process in which he once again uses an impressive array of data to show how introducing an FBS playoff system would not only be more equitable and revenue-enhancing across the board for all colleges and universities - and thus help reduce the gap between rich and poor athletic programs-but would also end an anticompetitive and self-serving structure that negatively impacts consumer welfare. My only quarrel with his analysis is the assertion that ending the current BCS system would "blunt the incentives to chase football success" (2010, p. 20) because a smaller financial payoff will result in schools having "less incentive to spend for coaches, for recruiting, for facilities, and the arms race should be slowed down" (p. 21). Unfortunately, I am far less sanguine than is Professor Zimbalist on this latter point. Though I very much support a playoff system for all the reasons he cites, I also believe that such a system will create even more pressure to win-because the stakes will become considerably higher to reach the playoffs - and thus increase rather than reduce the current arms race. But this feeling is based primarily on past experiences with the NCAA and men's college sports, where the rich always get richer no matter the reform, than it has anything to do with Zimbalist's overall analysis and predictions.

\section{Understanding the Role and Significance of Sport}

Given that there is universal agreement—from scholars, college presidents, athletic directors, the NCAA, the Knight Commission, and many others - that the financial challenges in intercollegiate athletics are greatly in need of structural reform, and that there appears to be no end in sight to the current state of affairs, one is tempted to ask if there is a counterforce at work which keeps any meaningful reforms at bay. As Professor Zimbalist suggests, when it comes to college sports, prestigious and powerful educational institutions engage in patterns of behavior that from a financial standpoint seem to go against their own best interests. Pointing out that overall spending in athletic departments is growing at four times the rate of the general educational budget, Zimbalist highlights the key take away from this spend- 
ing pattern: "Only if athletics investment yields higher returns than, say, investing in excellent faculty, science laboratories or growing the development office would it make economic sense to increase spending on athletics" (2010, p. 7). This point becomes even more critical because subsidies to athletic departments from institutional coffers are rising faster than are educational subsidies for the student body overall (Weiner \& Suggs, 2009).

Those who have studied the impact, role, and significance of sports in U.S. culture may provide some answers. As I myself have argued in a different context, Did you ever wonder why it's "News, Weather, and Sports"? Why not News, Weather, and Technology? Why don't we highlight education? Or literature? (Kane, 2007). The significance of sports in our everyday lives is reflected in the investments we make both literally and figuratively. As Jay Coakley (2007) has noted, sports hold such prominence in our society because, "[they] produce vivid images and lively stories that entertain and inspire people and provide them with the words and ideas that they use to make sense of their experiences and the world around them" ( $p$. 19). One of the many intangible yet profoundly meaningful aspects of sport is the way in which this all-pervasive institution serves as a unifier of people. A powerful example of this was the role sports took on in the aftermath of September 11. All across this nation, in sports stadiums big and small, Americans came together to reaffirm our basic values and principles. Returning to Coakley's analysis, participation in sports is a critical component of the socialization process, and also engenders a sense of personal identity, group membership or belonging, and social identification. The key point here is that while none of these elements of sport can be easily measured in financial terms, they go a long way in explaining why there is such resistance (or at least intransigence) when it comes to enacting deep and meaningful financial reforms.

At the college level, sports are often at the center of - and even create-a sense of identity and community, along with engendering feelings of local and national pride for one's team, university, and state. This too is often hard to measure in strictly financial terms. And speaking of financial concerns, we should not overlook the following reality: Just as sport spending sprees have put enormous pressures on the fiscal stability of institutions of higher education, college sports programs have also attracted millions of recurring dollars to those very same institutions. In TV contracts alone, CBS has an 11-year \$6 billion commitment to the NCAA to broadcast the Final Four in men's basketball (Sandomir, 2009). And most BCS conferences have negotiated their own deals to set up conference television networks. ${ }^{2}$ For example, in 2007, the Big 10 entered into a 20-year partnership with Fox to launch the Big Ten Network. This translates into each of the 11 schools in the Big 10 receiving $\$ 6$ million on an annual basis. When you add that figure to the Big 10's contracts with CBS and ESPN (where each institution receives an additional \$9.3 million annually) you end up with every institution receiving approximately $\$ 15$ million a year. And these numbers are even greater in the SEC conference (Smith \& Ourand, 2008). I make this point to help explain, in part, why efforts at reform of big-time college sports, especially when it comes to the ever-increasing arms race, seem to always be beyond our intentions and capabilities.

There is one final issue which I believe more fully explains why big-time sports in general, and college sports in particular, remain relatively unscathed when it comes to efforts at structural reform, and also why educational institutions 
routinely act against their own best financial interests. Relying on analyses and insights provided by sport sociologists, we should never underestimate the role of sport in maintaining and reinforcing ideologies and practices of male power and privilege. Numerous scholars have long argued that one of sport's many functions is to serve as a central site for the production of male supremacy and hypermasculinity, not only in the sportsworld, but in the larger social order (Allain, 2008; Birrell \& McDonald, 2000; Coakley, 2009; Duncan \& Messner, 1998; Kane \& Buysse, 2005). For example, we are reminded on a daily basis that males run faster, hit harder, and jump higher than do females. As a result, sports such as football reinforce the notion that females are not only "other than" but "less than" their male counterparts. Mike Messner made this point two decades ago and it remains relevant_-and equally important_-in today's sports culture:

... based on the most extreme possibilities of the male body [football] is clearly a world apart from women, who are relegated to the role of cheerleading/sex objects on the sideline...the armored male bodies... are elevated to mythical status, and as such, give testimony to the undeniable "fact" that here is. . one place where men are clearly superior to women. (1990, p. 213)

I stress this line of reasoning because men's sports, particularly football and basketball, are spectacles of male superiority writ large, and thus play a critical role in maintaining the balance of (male) power in the post-Title IX era, where, in spite of significant inroads made by sportswomen, they remain second on the priority list when it comes to an institution's commitment to investing resources. What does all of this have to do with Professor Zimbalist's critique of a financial system that is on the brink of disaster? Big-time sports are, by definition, male sports. Attempts to curtail, limit, or downsize what is at the very core of big-time college athletics - money and power-may be seen as a direct threat not just to sports overall, but to the "natural" order of male supremacy. My point here is that any serious challenge to the status quo-and structural financial reforms would certainly qualify - could be interpreted as a change that may fundamentally alter the balance of power and would therefore be (and is) fiercely resisted. This is the "force greater than nature" I referred to earlier in the paper when talking about why college presidents routinely shy away from trying to enact significant reforms.

\section{A Modest Proposal}

In this final section of the paper I offer my own suggestions for bringing about meaningful and long-lasting reform. For several years I have taught a course called Sport and Society at the University of Minnesota. It's a popular class which attracts both upper level undergraduate and graduate students. A number of these students are also scholarship athletes. Not surprisingly, the majority of all students in the class are quite interested in-and well versed about - the world of sports. A key component of the course is to examine the numerous myths and realities surrounding big-time college sports, particularly when it comes to Title IX and the widespread (though inaccurate) belief that football is the "golden goose" that not only pays for itself, but also subsidizes men's nonrevenue sports along with all women's sports. 
When I share with my students many of the points that Professor Zimbalist makes, and rely on similar data to do so, there is, if not great reluctance, at least a persistent skepticism whereby they find it hard to believe (accept?) the notion that, in fact, the vast majority of athletic departments run major deficits and are routinely subsidized by their university's central administration to keep them afloat. They also resist (at least initially) the assertion that football programs are far from the cash cows they are made out to be, and are, in most instances, enormous drains on the overall sports programs. These students are not alone in their beliefs: A recent report sponsored by the Knight Commission found that $78 \%$ of those surveyed believed that college sports programs were profitable (Knight Commission on Intercollegiate Athletics, 2006). And how could they not believe this to be the case? Every year during football season we are bombarded with images (and realities) reflected in 24-7 sports coverage, tailgates, prognostications, and filled-to-capacity stadiums. Big stage, big stakes, big money.

While it is certainly the case that most FBS schools generate enormous sums of revenue, we simultaneously overlook, or ignore altogether, the other side of the ledger, meaning what does it cost to put these same teams on the field? When I provide my students with this elemental-in-financial-terms framework of analysis, the fog lifts and they are eager-or at least open to-hearing the other side of the story. At this point, the first and most central argument I make is that we must distinguish between revenue producing versus profit generating financial models. As a recently released report from the NCAA makes clear, it is simply a myth that men's basketball and football not only cover their own expenses but fully support nonrevenue sports. During the 2007-08 school year alone, 93 athletic departments ran a deficit with losses averaging just under \$10 million (Weiner \& Suggs, 2009).

How does all of this translate into specific, practical suggestions for bringing about much-needed change? I would urge advocates of reform, from scholars and educators, to athletic administrators and coaches, to members of the NCAA, the Knight Commission, and other like-minded groups, to launch a massive and sustained educational campaign that would dispel the myths that keep the status quo in place and make efforts at reform an uphill battle. ${ }^{3}$ Along with countering the notion that "football saves us all" there are two other powerful and deeply embedded myths surrounding financial spending patterns and athletic success. The first relates to the age-old adage that you have to spend more to make more. This philosophy explains, in part, why presidents and athletic directors invest so much money on recruitment budgets, can't-miss power coaches, and never-ending facility upgrades. But as Litan, Orszag, and Orszag (2005) discovered in a report sponsored by the NCAA, there is no significant correlation between winning on the field and increased spending by athletic departments. This finding is particularly troubling when you compare it to results from the 2009 Knight Commission survey: In spite of the widespread concern expressed by university presidents about the out-of-control arms race in intercollegiate athletics, many of them nevertheless expressed a desire to "increase [spending] rather than opt out of the system or push for systemic change" (Moltz, 2009). A second and related myth involves the belief that paying enormous sums of money to football and men's basketball coaches will lead to increased revenues as well as a winning team. According to a 2005 Knight Commission report, this common-sense notion is equally untrue (Weiner \& Suggs, 2009). 
These powerful yet rarely challenged myths — at least outside of the academysuggest targets, avenues, and openings for a sustained educational campaign as an effective counterforce. Let's take the recent, and I would argue egregious, example of the University of Kentucky's hire of men's basketball coach, John Calipari. Critics have noted that even though the University could (theoretically) afford to pay him \$31.65 million over eight years (SportsBusiness Daily, 2009), his contract was negotiated during the same time period the University absorbed a $2 \%$ budget cut from the state legislature which resulted in 20 faculty positions being frozen or eliminated altogether. And it wasn't just the faculty who were impacted by these budget cuts. Because the University took a $\$ 20$ million shortfall in state aid, the "trustees voted to cut 15 staff members and eliminate 170 unfilled jobs" (Miller, 2009). There may have been a sense of outrage (at least among some faculty and staff), but I would guess that most Kentuckians, along with countless other Americans, believe that in the long run, the University would more than make up for the budget cuts because they are confident that Calipari would produce a winning program. My belief (or at least hope) is that agents of reform would establish as fact that even if Calipari did so, it wouldn't automatically result in increased revenues.

A central piece of my proposed educational campaign would be to rely on the work of the individuals attending this research colloquium and further, that it would begin with the information provided by Professor Zimbalist in his keynote address. Those engaged in reform might be considered "myth busters" which to my mind would be considered an upgrade from "egg heads." On a more serious note, I suggest that if the deeply seated and culturally embedded myths outlined above are truly exposed for what they are, it would create great pressure on-and give political cover to- - university presidents and the NCAA. Imagine a scenario where athletic directors are judged, at least in large measure, on how fiscally responsible they are being and not just (or primarily) on the win/loss records of their men's basketball and football teams. And what would it look like if critics began to argue that those presidents who all too willingly follow what their ADs want may be in jeopardy of breaching their fiduciary duties to their institutions? ${ }^{4}$

Like Professor Zimbalist, I have no illusions that meaningful reform of what is clearly a broken system will get any easier or come anytime soon. This is not to suggest that those of us who care about reform - especially tenured faculty who, in my view, have a particular responsibility to take this challenge on-should throw up our hands in defeat or engage in the depressingly pessimistic views offered by university presidents in the oft-mentioned Knight Commission Survey. One of the many lessons that sports teach us is that there is always another contest just around the corner. I have a strong suspicion that Professor Zimbalist will be waiting for us there.

\section{Notes}

1. The Coalition on Intercollegiate Athletics (COIA) is "a group advocating for reform in intercollegiate athletics, created by and representative of faculty senate leaders at Bowl Championship Series conference schools" (COIA, 2003). The Coalition's goal is to ensure inclusion of faculty members in reform efforts designed to make sure intercollegiate athletics augments a university's academic mission. 
2. Currently, the Big 10, Big 12, SEC, and Big East have their own sports networks. In May 2010, the ACC signed a multi-million dollar contract with ESPN; the Pac 10 is also seeking its own television contract.

3. The Washington Post editorial written by William Kirwan and Gerald Turner is one example of such a media campaign. They powerfully and succinctly challenged many of the widespread myths related to the "football is the golden goose that pays for everybody" narrative. In addition, their position as cochairs of the Knight Commission gives them great credibility as does the location of their editorial - the Washington Post is one of the most well-respected newspapers in the country.

4. I am indebted to my colleague at the University of Minnesota, Rayla Allison, J.D., who pointed out that there is a body of law called "agency law" whereby one party (the agent or university president) agrees to act in the best interest and with loyalty (fiduciary duties) to the principal (other party or institution in question). I am not suggesting that advocates of reform use this particular law to bring, for example, lawsuits against university presidents. What I am suggesting is that this legal principle be considered as part of a broader array of strategies in pushing for change.

\section{Acknowledgments}

The author would like to thank Shari Ballard, Marta Fahrenz, and Jonathan Sweet for their contributions to this manuscript.

\section{References}

Allain, K.A. (2008). "Real fast and tough": The construction of Canadian hockey masculinity. Sociology of Sport Journal, 25(4), 462-481.

Birrell, S., \& McDonald, M.G. (2000). Reading sport: Critical essays on power and representation. Boston: Northeastern University Press.

Coakley, J. (2007). Sports in society: Issues and controversies (9th ed.). Boston: McGraw Hill.

Coakley, J. (2009). Sports in society: Issues and controversies (10th ed.). Boston: McGraw Hill.

Coalition on Intercollegiate Athletics. (2003, March). Charter of the Coalition on Intercollegiate Athletics. Retrieved December 17, 2009, from http://coia.comm.psu.edu/ Charter.html

Duncan, M.E., \& Messner, M.A. (1998). The media image of sport and gender. In L.A. Wenner (Ed.), MediaSport: Cultural sensibilities and sport in the media age (pp. 170-185). London: Routledge.

Fulks, D. L. (2009). 2004-08 NCAA revenues and expenses of Division I intercollegiate athletics programs report. Retrieved December 23, 2009, from http://www.ncaapublications.com/ Uploads/PDF/Revenues_Expenses_10_208acb1ac8-caf1-42ad-9e1e-dc6c399c227b.pdf.

Kane, M.J. (2007). Sociological aspects of sport. In J.B. Parks, J. Quarterman, \& L. Thibault (Eds.), Contemporary sport management (3rd ed., pp. 389-413). Champaign, IL: Human Kinetics.

Kane, M.J., \& Buysse, J. (2005). Intercollegiate media guides as contested terrain: A longitudinal analysis. Sociology of Sport Journal, 22(2), 214-238.

Kentucky says Calipari's lucrative contract won't impact budget. (2009, April 2). SportsBusiness Daily. Retrieved December 18, 2009, from http://www.sportsbusinessdaily. com/article/129063

Kirwan, W.E., \& Turner, R.G. (2009, December 19). Playoffs not the answer to college football's crisis. Washington Post, A17. Retrieved December 22, 2009, from http://www. washingtonpost.com/wp-dyn/content/article/2009/12/18/AR2009121803510.html. 
Knight Commission on Intercollegiate Athletics. (1991, August). Keeping faith with the student-athlete: A new model for intercollegiate athletics. Retrieved December 2, 2009, from http://knightcommission.org/images/pdfs/1991-93_KCIA_report.pdf.

Knight Commission on Intercollegiate Athletics. (2006, January). Public opinion poll: Executive summary. Retrieved December 2, 2009, from http://knightcommission.org/ images/pdfs/pollresults1-20-06.pdf

Knight Commission on Intercollegiate Athletics. (2009, October). Quantitative and qualitative research with football bowl subdivision university presidents on the costs and financing of intercollegiate athletics: Report of findings and implications. Retrieved December 12, 2009, from http://www.knightcommissionmedia.org/images/President_ Survey_FINAL.pdf.

Lederman, D. (2009, October 30). Bad time for sports overspending. Inside Higher Ed. Retrieved October 30, 2009, from http://www.insidehighered.com/news/2009/10/30/ ucsports.

Litan, R.E., Orszag, J.M., \& Orszag, P.R. (2005). The empirical effects of collegiate athletics: An update. Retrieved December 28, 2009, from http://ncaa.org/wps/wcm/connect/974 83e804e0dabfa9f32ff1ad6fc8b25/empirical_effects_of_collegiate_athletics_update.pdf ?MOD=AJPERES\&CACHEID=97483e804e0dabfa9f32ff $1 \mathrm{ad} 6 \mathrm{fc} 8 \mathrm{~b} 25$.

Messner, M.A. (1990). When bodies are weapons: Masculinity and violence in sport. International Review of Sport Sociology, 25(3), 203-220.

Miller, J.R. (2009, April 2). Cash strapped states pay millions for basketball coaches. Fox News. Retrieved December 21, 2009, from http://www.foxnews.com/ story/0,2933,512227,00.html.

Moltz, D. (2009, October 27). Powerless, or passing the buck? Inside Higher Ed. Retrieved October 30, 2009, from http://www.insidehighered.com/news/2009/10/27/knight.

National Collegiate Athletic Association. (2009a). 2009-10 Division I travel policy quick reference guide. Retrieved December 12, 2009, from http://www.ncaa.org/ $\mathrm{wps} / \mathrm{ncaa} ? \mathrm{key}=/ \mathrm{ncaa} / \mathrm{ncaa} /$ sports+and+championship/general+information/travel/ di+travel+quick+reference.

National Collegiate Athletic Association. (2009b). The history of the NCAA. Retrieved December 12, 2009, from http://ncaa.org/wps/ncaa?key=/ncaa/ncaa/about+the+ncaa/ overview/history.html.

Sandomir, R. (2009, March 16). NCAA can opt out of deal with CBS after 2010. New York Times. Retrieved December 18, 2009, from http://www.nytimes.com/2009/03/17/sports/ ncaabasketball/17sandomir.html.

Smith, M., \& Ourand, J. (2008, August 25). ESPN to pay $\$ 2.25$ billion for SEC rights. Sporting News. Retrieved December 18, 2009, from http://www.sportingnews.com/ college-football/article/2008-08-25/espn-pay-225-billion-sec-rights.

Weiner, J., \& Suggs, W. (2009, October 3). College sports 101: A primer on money, athletics, and higher education in the $21^{\text {st }}$ century. Retrieved November 23, 2009, from http:// www.knightcommission.org/index.php?option=com_content\&view=article\&id=344 $\&$ Itemid $=84$.

Zimbalist, A. (2010). Dollar dilemmas during the downturn: A financial crossroads for college sports. Paper presented at the 2010 Scholarly Colloquium on College Sports, January, 2010, Atlanta, GA. 